\title{
REVIEW \\ Recombination Hot Spots and Human Disease
}

\section{Smita M. Purandare ${ }^{1}$ and Pragna I. Patel ${ }^{1-4}$}

\author{
Departments of ${ }^{1}$ Neurology, ${ }^{2}$ Molecular and Human Genetics and ${ }^{3}$ Division of Neuroscience, Baylor \\ College of Medicine, Houston, Texas 77030
}

Recombination between homologous DNA sequences occurs in all organisms, and the resultant exchange of information is critical for the survival of species. Recombination is an essential cellular process catalyzed by proteins explicitly expressed for this purpose. It provides an effective means of generating genetic diversity that is important for evolution. The proteins involved in recombination allow cells to retrieve sequences lost when DNA is damaged by radiation or chemicals, by replacing the damaged section with an undamaged strand from a homologous chromosome. The process of homologous recombination has also been used to study gene function by way of gene knockouts. However, recombination and factors involved in recombination may also be a source of harmful mutations and disease.

Specific DNA sequences are known to mediate or enhance the rate of recombination in the genomes of many organisms. Attempts to identify and decipher recombination hot spots have focused on determining the influence of various DNA sequences on the rate and type of DNA rearrangements. The human nuclear genome contains a large number of highly repeated DNA sequence families (Jelinek and Schmid 1982; Hardman 1986; Vogt 1990), broadly classified as tandemly repeated DNA or interspersed repetitive DNA. Because of their role in mediating disease-causing recombination errors, a brief overview of the various repeats is presented.

Tandemly repeated DNA is characterized by blocks or arrays of tandemly repeated DNA sequences. They are subclassified based on the size of the blocks or arrays of tandem repeats into satellite $(0.1$ to $>2 \mathrm{Mb})$, minisatellite $(0.1-2.0 \mathrm{~kb})$, and microsatellite ( 150 bp) DNA. Satellite DNA is further sub-classified based on the size of the repeat unit within these blocks into types 1 (25-48 bp), 2 and 3 (5 bp), $\alpha$ (alphoid DNA; 171 bp), and $\beta$ (Sau3A family; $68 \mathrm{bp}$ ). Minisatellite DNA consists of telomeric DNA that has a 6-bp repeat unit, and the polymor-

${ }^{4}$ Corresponding author.

E-MAIL pragna@bcm.tmc.edu; FAX (713) 798-8526. phic VNTRs (variable number tandem repeats) or hypervariable minisatellite DNA, where the size of the repeat unit ranges from 9 to $24 \mathrm{bp}$. VNTRs have been shown to be hot spots for homologous recombination in human cells (Wahls et al. 1990). Microsatellite DNA consists of small arrays of tandem repeats (usually 1-4 bp units) that are interspersed throughout the genome, in blocks consisting of $<150$ bp.

In contrast to tandemly repeated DNA, interspersed repetitive DNA consists of repeat units dispersed throughout the genome. Based on the repeat unit length, two major classes are recognized: short interspersed nuclear elements [(SINES) e.g., the Alu repeat family] and long interspersed nuclear elements [(LINES) e.g., the LINE-1 or L1 element (Singer 1982)]. The Alu repeat containing a 280-bp repeat unit occurs approximately once every $4 \mathrm{~kb}$ in the human genome. Mispairing between such repeats has been shown to be a frequent cause of deletions and duplications. Breakpoints of diseasecausing deletions have been clustered within Alu sequences in genes for the low density lipoprotein receptor (LDLR) (Lehrman et al. 1985, 1987), and the complement component 1 inhibitor (C1I) (Stoppa-Lyonnet et al. 1991). Such observations have suggested a general role for Alu sequences in promoting recombination and recombination-like events. Alu repeats or other dispersed repetitive elements are also thought to have played a role in the evolution of clustered multigene families by mediating unequal crossover events that lead to gene duplications. The average length of the L1 element repeat unit is $1.4 \mathrm{~kb}$. In addition, there are smaller repeat sequence families belonging to this class, including the THE-1 (transposable human el ements), MER (medium reiteration), HERV (humān endogenous retroviruses), and RTLV (retrovirus-like elements) repeats. Members of many of the interspersed repeat families are considered retrotransposable elements, that is, unstable DNA elements that can migrate to different regions of the genome by transposition via an RNA intermediate. These endogenous retroposons are thought to have played an important role in shaping the genomes of verte- 
brates by intracellular transposition events and by generating hot spots of recombination (Leib-Mosch and Seifarth 1995).

The various families of repetitive elements are highly relevant to a number of different mechanisms of mutagenesis in human genes. As discussed in the following sections, recombination between such sequences can lead to rearrangements, including deletions, duplications, inversions, and fusion genes.

Deletions and Duplications Caused by Homologous Recombination

Hot spots of homologous recombination between misaligned repetitive el ements have been observed at the duplication and deletion breakpoints in a number of human genetic diseases. In Escherichia coli, direct repeats in close proximity can mediate efficient RecA-independent intramolecular recombination. A replicational model for DNA recombination between direct repeats was suggested by $\mathrm{Bi}$ and Liu (1996). They proposed that misalignment of repeats at the replication fork creates a recombinogenic intermediate that can be differentially processed and that the proposed sister-strand recombination mediated by direct repeats might be a general mechanism of deletion or duplication of repeated sequences in prokaryotic and eukaryotic genomes.

Large-scale deletions and duplications may be generated by the pairing of nonallelic interspersed or tandem repeats, followed by breakage and rejoining of chromatid fragments. Repeat DNA sequences may predispose to abnormal chromosome pairing and unequal crossingover, with deletions and duplications representing the reciprocal products of such events. Large deletions within duplicated regions may occur either interchromosomally because of misalignment of non-sister chromatids during gene. meiosis (Pentao et al. 1992; Chance et al. 1994) or intrachromosomally because of either sister chromatid exchange during mitosis or DNA slippage during replication (Krawczak and Cooper 1991).

Charcot-Marie-Tooth disease type 1A (CMT1A) and hereditary neuropathy with liability to pressure pal sies (HNPP) are two autosomal dominant peripheral neuropathies resulting from DNA rearrangements that are reciprocal products of an unequal crossing-over event between misaligned flanking CMT1A-REP (repeat) elements on chromosome 17p (Chance et al. 1994; Patel and Lupski 1994) (Fig. 1). The proximal and distal CMT1A-REP elements are $\sim 30 \mathrm{~kb}$ in length, extremely AT rich $(64 \% \mathrm{~A}+\mathrm{T})$, and display $98 \%$ sequence identity (Reiter et al. 1996). Given the high degree of homology between the proximal and distal repeats, a recombination event can potentially occur anywhere within the 30-kb region. However, through the detection of novel junction fragments from the recombinant CMTIA-REP elements in both CMTIA and HNPP patients, a 1.7-kb recombination hot spot within the $\sim 30-k b$ CMTIA-REP was identified in $75 \%$ of

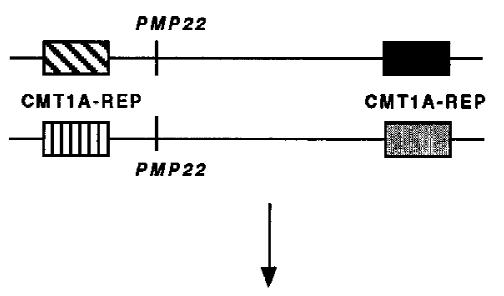

UNEQUAL CROSSING OVER DUE TO MISALIGNMENT AT MEIOSIS

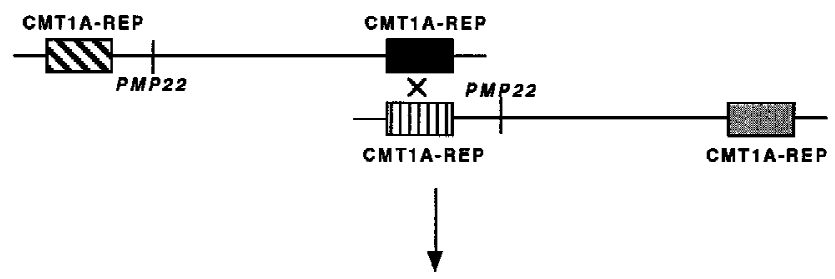

RECIPROCAL PRODUCTS OF RECOMBINATION
CMT1A DUPLICATION

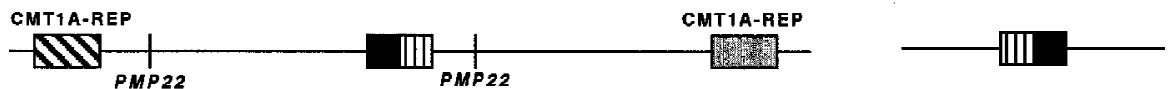

Figure 1 Generation of the CMT1A duplication and HNPP deletion attributable to unequal crossing-over. The proximal and distal CMT1A-REP elements (boxes) flanking the 1.5-Mb region containing the PMP22 gene (vertical line) on two different chromosomes are depicted. Unequal crossing-over because of misalignment at meiosis between the distal and proximal CMT1A-REP elements results in two reciprocal recombination products: the CMT1A duplication (3.0 Mb) chromosome with two PMP22 genes and the HNPP deletion (1.5 Mb) with no PM P22 
CMT1A duplication patients and $84 \%$ of HNPP deletion patients examined (Reiter et al. 1996). Sequence analysis showed there was no particular increase in the degree of sequence identity over this 1.7-kb region, and, interestingly, a mariner transposon-like element (MITE) was identified in the vicinity of the hot spot. Three exons were identified in the repeat, one of which showed homology at the amino acid level to the conserved region of several insect transposases. Kiyosawa and Chance (1996) further investigated the MITE and found that it is probably nonfunctional, as several stop codons were found in its open reading frame. However, it is possible that this nonfunctional mariner sequence may be a target for a functional form of the transposase protein transcribed from a gene located elsewhere.

Northern blot analysis with the distal CMT1AREP, which encompasses the putative transposase, identified a low-abundance transcript expressed in testes but not in ovaries (Reiter et al. 1996). This finding was interesting, because until recently it was considered that the unequal crossing-over resulting in CMT1A and HNPP occurred solely during male meiosis. Investigation of the origin of de novo duplications revealed a paternal origin for the mutation in 13 sporadic cases (Raeymaekers et al. 1991; Pal au et al. 1993; Wise et al. 1993; Hertz et al. 1994). Palau et al. (1993) proposed that male-specific factors may operate during spermatogenesis to help form the duplication and/or stabilize the duplicated chromosome. However, Blair et al. (1996) on analysis of de novo duplications in eight families, found seven to be paternal and one, the first reported, to be maternal in origin, indicating that this was not a phenomenon associated solely with male meiosis. Two loci within the duplication region (D17S122 and D17S61) that were physically mapped within $1.0 \mathrm{Mb}$ of each other were found to span an average genetic distance of $4 \mathrm{cM}$ in males and $14 \mathrm{cM}$ in females (Pentao et al. 1992). This large discrepancy between the genetic and physical distances of these duplicated markers suggests that this region appears to be extremely prone to meiotic recombination. Because recombination fractions for the duplicated region in CMT1A are larger in females than in males, oogenesis may afford greater protection from misalignment during synapsis, and/or there may be lower activity of those factors or mechanisms that lead to unequal crossing-over at the CMT1A locus (Blair et al. 1996).

Allelic variants of the human cytochrome P450 CYP2D 6 gene have also been shown to arise from homologous unequal crossing-over involving a 2.8$\mathrm{kb}$ direct repeat (Steen et al. 1995). The cytochrome
P450 enzyme debrisoquine 4-hydroxylase metabolizes many different classes of commonly used pharmacological drugs. Among Caucasians, 5\%-10\% are classified as poor metabolizers (PM) because of autosomal recessive inheritance of two CYP2D 6 deletion alleles. In these individuals, administration of average therapeutic doses results in toxic plasma concentrations and adverse drug reactions. In contrast, up to $5 \%$ demonstrate ultrarapid metabolism (UM) caused by an inherited duplication of functional CY P2D 6 genes, thus requiring higher doses of drugs to maintain desired plasma levels. A 2.8-kb repeated sequence (CYP-REP), containing an Alu element and a tandem 10-bp direct repeat flanks the active CYP2D 6 gene in the wild-type allele. It is thought that the CYP2D 6 deletion and duplication alleles are reciprocal products, generated by homologous recombination between nonallelic CYPREP elements.

Large-scale rearrangements are detected in $80 \%$ of familial and $65 \%$ of sporadic cases of juvenile nephronophthisis (NPH), representing the most frequent inherited cause of chronic renal failure in children (Konrad et al. 1996). Large homozygous deletions (250 kb) involving a 100-kb inverted duplication were found at the NPH 1 locus on chromosome $2 q 13$. Further characterization of this region revealed the presence of low-copy repeats.

$X$-linked icthyosis is a disease characterized by an extremely high frequency of submicroscopic deletions involving the steroid sulfatase (STS) gene (Bonifas et al. 1987; Conary et al. 1987; Ballabio et al. 1989a,b). Eighty-four percent of patients with steroid sulfatase deficiency possess deletions of their STS genes (10 exons spanning $146 \mathrm{~kb}$ of genomic DNA). The deletions have breakpoints clustered around or within a number of low-copy repetitive sequences called S232 type repeats, flanking the STS gene (Yen et al. 1990). These repeats resemble VNTRs (Li et al. 1992) and indicate that the high frequency of deletions at this locus may be attributable to recombination involving these repetitive sequences.

Deletion of both growth hormone (GH1) genes causes the autosomal recessive disease familial growth hormone deficiency type $1 \mathrm{~A}$. In 9 of 10 patients with $\mathrm{GHI}$ gene del etions, the crossovers occur within two 99\% homologous, 594-bp regions flanking the GH1 gene (Vnencak-Jones et al. 1988; Vnencak-Jones and Phillips 1990). The presence of these highly homologous DNA sequences flanking the GH1 gene predisposes recurrent unequal recombination events.

Fascioscapulohumeral muscular dystrophy 
(FSHD) is an autosomal dominant neuromuscular disease that has been linked to deletions within a tandem array of 3.2-kb repeats (D4Z4) adjacent to the telomere on chromosome 4q35 (van Deutekom et al. 1993). The majority of sporadic cases of FSHD are associated with de novo deletions at the D4Z4 locus. The D4Z4 sequence contains two homeoboxes and two previously described repetitive sequences, LSau and a GC-rich low-copy repeat designated hhspm3 (Hewitt et al. 1994; Lee et al. 1995). D4Z4 is a member of a dispersed family of homeobox-containing repeats, subsets of which are clustered on the short arms of acrocentric chromosomes (Lyle et al. 1995). Analysis of the evolutionary distribution and structural organization of D4Z4 showed that tandem arrays closely related to D4Z4 were conserved at loci syntenic to human 4q35-qter in apes and lower primates, suggesting a functionally important role for these sequences (Clark et al. 1996; Winokur et al. 1996). However, no single gene has yet been associated with FSHD, and the etiopathogenesis of FSHD is not yet known. It has been proposed that the deletions mediated by these repeat sequences may invoke a position effect on a nearby gene.

The most common molecular defect underlying $\alpha$ thalassemia involves a deletion of one or both of the duplicated $\alpha$-globin genes (Dozy et al. 1979; Higgs et al. 1979). The mechanism by which the $\alpha$ thalassemia deletions occur is related to the underlying molecular structure of the $\alpha$-globin complex (Embury et al. 1980; Lauer et al. 1980). Each $\alpha$ gene is located within a region of homology, $\sim 4 \mathrm{~kb}$ long (thought to have resulted from an ancient duplication event), and interrupted by short nonhomologous regions. During evolution, these homologous segments were divided by insertions and deletions to give rise to three homologous subsegments referred to as $X, Y$, and $Z$. The duplicated $Z$ boxes are $3.7 \mathrm{~kb}$ apart, and the duplicated $X$ boxes are $4.2 \mathrm{~kb}$ apart. Misalignment and reciprocal crossover between these segments at meiosis give rise to chromosomes with either single (Embury et al. 1980) or triplicated $\alpha$-globin genes (Goossens et al. 1980). Recombination between the homologous $X$ or $Z$ boxes (4.2 or $3.7 \mathrm{~kb}$ apart) gives rise to chromosomes with a 4.2 - or $3.7-\mathrm{kb}$ del etion with one $\alpha$-globin gene and the reciprocal chromosome with three $\alpha$-globin genes. Although the breakpoints of these deletions vary within these regions of homology, the mechanism of homologous unequal recombination appears to be the same. These recombination events have been reported in several ethnic groups (Higgs et al. 1989).

\section{Inversions Caused by Homologous Recombination}

Occasionally, highly similar inverted repeats may be located within or close to a gene. The high degree of sequence similarity between inverted repeats may predispose to pai ring of the repeats by a mechanism that involves a chromatid bending back on itself. Subsequent chromatid breakage at the mispaired repeats and rejoining can result in an inversion, thus disrupting a functional gene. An example of pathogenic inversions caused by such a mechanism is seen in hemophilia A. Forty-five percent of patients with severe hemophilia A have an inversion and disruption of the coagulation factor VIII gene mediated by an unequal crossing-over event (Lakich et al. 1993). Within intron 22 of the factor VIII gene lies another gene, F8A, which has two additional copies situated $500 \mathrm{~kb}$ upstream (telomeric) of the factor VIII gene on $\mathrm{Xq}$ but in the opposite orientation. Evidence suggests that the tip of Xq flips back on itself, aligning the homologous intragenic and extragenic F8A sequences in meiosis. Unequal crossing-over results in recombination between one of the upstream genes and the intragenic F8A gene, generating an inversion of the intervening factor VIII gene sequence (Fig. 2). Such inversions result in disruption of the factor VIII gene, separating exons 1-22 from exons 23-26 by 200-500 kb. As the single $X$ chromosome in males remains largely unpaired in meiosis, the tip of the chromosome is free to flip up on itself-a phenomenon that does not occur in female meiosis, where both $X$ chromosomes pair along their length like autosomes, apparently restricting the movement of Xqter. Rossiter et al. (1994) hypothesized that pairing of Xq with its homolog inhibits the inversion process and, therefore, the event should originate predominantly in male germ cells. They examined 20 informative cases in which the inversion originated in a maternal grandparent, and by analysis of DNA polymorphisms determined that it occurred exclusively in the male germ line. In addition, they showed that all but one of the 50 mothers of sporadic cases resulting from an inversion were carriers. These data supported their hypothesis that factor VIII gene inversions leading to severe hemophilia A occurred exclusively in male germ cells.

Another example of an inversion caused by homologous recombination is that involving the iduronate-2-sulfatase (IDS) gene. Deficiency of the enzyme IDS results in Hunter syndrome, an X-linked recessive disorder al so known as mucopolysaccharidosis II. A linked IDS pseudogene-like sequence (IDS2) was detected $\sim 90 \mathrm{~kb}$ downstream of the IDS 
gene (Bondeson et al. 1995; Rathmann et al. 1995). This region is involved in a homologous recombination event with the IDS gene in $20 \%$ of patients with Hunter syndrome (Bondeson et al. 1995). The intrachromosomal recombination between homologous sequences present in the ID S gene and the IDS2 locus results in disruption of the IDS gene in intron 7 with an inversion of the intervening DNA. No detectable del etions or insertions are observed as a result of this inversion event.

Unequal exchange between large homologous repeats leading to genome variation in the absence of disease-causing mutations was reported recently in the Xq28 region, which harbors the neighboring genes for filamin (FLN1) and emerin (Small et al. 1997). Flanking the 48-kb FLN 1/emerin region are two large inverted repeats, $11.3 \mathrm{~kb}$ in length, that exhibit 99\% sequence identity (Chen et al. 1996). During the characterization of a rare mutation involving a complete deletion of the emerin gene and a partial duplication of the FLN 1 gene in a patient with Emery-Dreifuss muscular dystrophy (EMD), a common rearrangement resulting from mispairing of these large repeats was identified (Small et al. 1997). Recombination betweeen these inverted repeats leads to a complete inversion of the 48-kb FLN1/emerin region without any sequence alteration in either gene. This inversion was detected in the heterozygous state in $33 \%$ of normal females and helps explain the discrepancies between the genetic and physical map distances in this region of the $X$ chromosome (Small et al. 1997). These investigators speculate that regional variation in the genetic map of humans may reflect the influence of similar, as yet uncharacterized, inversions mediated by large inverted repeats.

\section{Fusion Genes Generated by}

Recombination

Besides deletions, duplications, inversions, or other rearrangements, recombination between homologous sequences also results in the creation of fusion genes. Sequence homology between members of gene families or pseudogenes results in such rearrangements.
Several hemoglobin variants containing fused or hybrid globin chains have been described. Hemoglobin Lepore (Hb Lepore) was the first to be reported and is an example of gene fusion resulting from the deletional removal of intervening DNA sequence (Gerald and Diamond 1958). This hemoglobin, which is synthesized in reduced amounts, is an abnormal molecule with the amino-terminal 50-80 amino acids of $\delta$-globin and the carboxy-terminal $60-90$ residues of $\beta$-globin. The reduction in globin synthesis is caused by the reduced synthesis of mRNA encoding the fusion product to a level intermediate between those of the $\delta$-globin and $\beta$-globin genes. Thus, $\mathrm{Hb}$ Lepore contains normal $\alpha$ chains, and its non- $\alpha$ chain is a $\delta-\beta$ fusion chain. Three different varieties of $\mathrm{Hb}$ Lepore have been described ( $\mathrm{Hb}$ Lepore Hollandia, $\mathrm{Hb}$ Lepore Baltimore, and $\mathrm{Hb}$ Lepore Boston), in which the transition from $\delta$ to $\beta$ occurs at different positions (Baglioni 1962; Barnabus and Muller 1962; Ostertag and Smith 1969). Misalignment of chromosome pairing during meiosis results in pairing of the $\delta$-chain gene with the $\beta$-chain gene instead of its homologous partner. The fusion chains arise by nonhomologous crossingover between part of the $\delta$ locus on one chromosome and part of the $\beta$ locus on the complementary

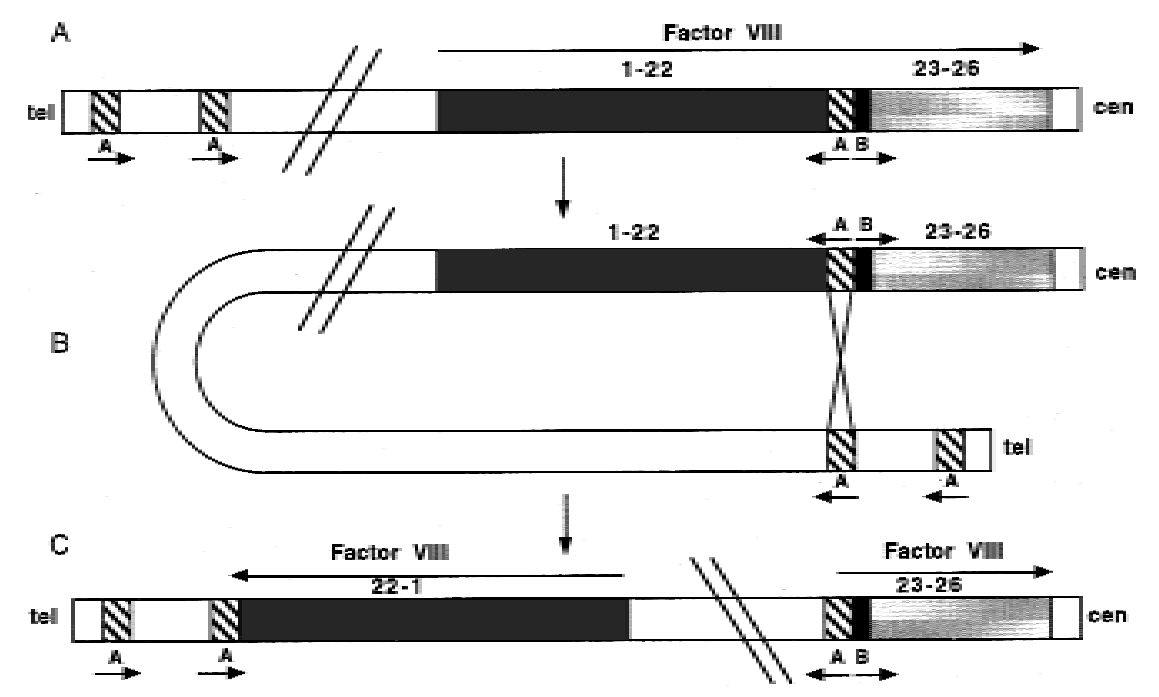

Figure 2 Inversion and disruption of the factor VIII gene mediated by the F8A gene in intron 22. (A) The genomic organization of the factor VIII gene showing the position and orientation of the three copies of the F8A genes (A) (two upstream of factor VII and one within intron 22) and one copy of the F8B gene $(B)$ within intron 22. Arrows indicate the direction of transcription of the factor VIII, A and B genes. (B) The homologous F8A sequences (A) within and outside the factor VIII gene mediate intrachromosomal recombination with the proximal A gene (presented here) or distal A gene. (C) The recombination product resulting in an inversion and disruption of the factor VIII gene. 
chromosome (Fig. 3). This mechanism gives rise to two abnormal chromosomes: the Lepore chromosome, which has no normal $\delta$ or $\beta$ loci but has a $\delta-\beta$ fusion gene, and the anti-Lepore chromosome, with a $\beta-\delta$ fusion gene ( $\mathrm{Hb}$ anti-Lepore) and normal $\delta$ or $\beta$ loci. A variety of anti-Lepore hemoglobins have been described, including $\mathrm{Hb}$ Miyada, $\mathrm{Hb}$ P-Congo, $\mathrm{Hb}$ Lincoln Park, and $\mathrm{Hb}$ Nilotic (Lehmann and Charlesworth 1970; Ohta et al. 1970; Badr et al. 1973; Honig et al. 1978). Hemoglobin Kenya is analogous to $\mathrm{Hb}$ Lepore, except that the abnormal hybrid chain is a $\gamma-\delta$ fusion chain (Huisman et al. 1972). The anti-Kenya chromosome contains intact $A_{\gamma^{-}}, \delta-$, and $\beta$-globin loci. The Lepore variants result in the clinical phenotype of $\beta$ or $\delta \beta$ thal assemia. The anti-Lepore variants and $\mathrm{Hb}$ Kenya are not associated with any significant hematolgical changes.

Unequal crossover or unequal sister chromatid

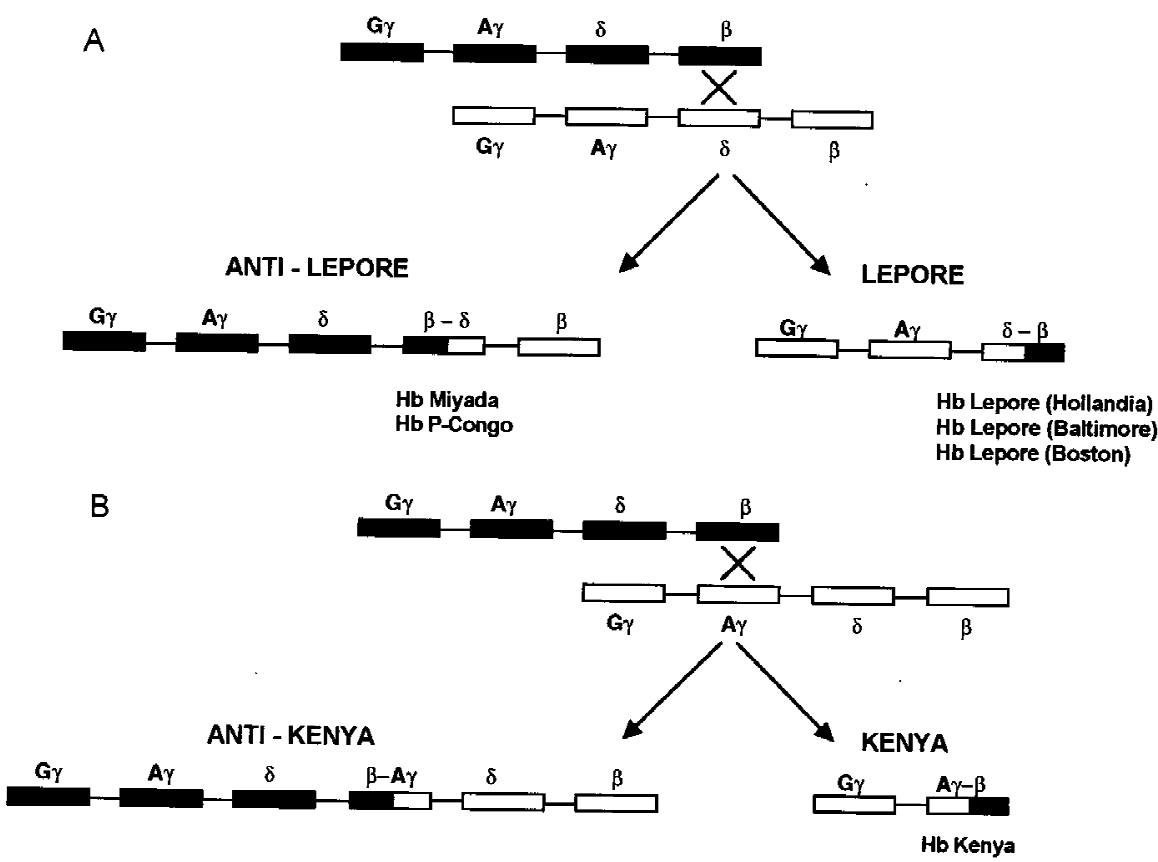

Figure 3 Fusion genes resulting from unequal crossing-over at the $\beta$-globin gene cluster. Genes within the $\beta$-globin gene cluster are shown. Fusion genes arising from unequal crossing-over between the $\beta$ and $\delta$-globin genes $(\mathrm{Hb}$ Lepore/anti-Lepore) and the $\mathrm{A}_{\gamma}$ and $\beta$ genes (Hb Kenya/anti-Kenya) are shown in $\mathrm{A}$ and $\mathrm{B}$. (A) The generation of $\mathrm{Hb}$ Lepore and $\mathrm{Hb}$ anti-Lepore: The different types of $\mathrm{Hb}$ anti-Lepore fusion alleles that have been described include $\mathrm{Hb}$ Miyada and P-Congo, where the crossover regions occur between residues $\beta 12$ and $\delta 22$ and between residues $\beta 22$ and $\delta 87$, respectively. The different types of $\mathrm{Hb}$ Lepore alleles that have been described are $\mathrm{Hb}$ Lepore Hollandia, Baltimore, and Boston, where the crossover regions occur between residues $\delta 22$ and $\beta 50$, residues $\delta 50$ and $\beta 87$, and residues $\delta 87$ and $\beta 116$, respectively. (B) The generation of $\mathrm{Hb}$ Kenya and $\mathrm{Hb}$ anti-Kenya: For Hb Kenya, the crossover region is between residues $\gamma 81$ and $\beta 86$. No Hb anti-Kenya variants have been described. exchange between a functional gene and a related esendo in deletion of the functional or formation of fusion genes containing a segtions into the functional gene. In steroid 21hydroxylase deficiency, virtually all pathological mutations arise as a result of sequence exchanges between the functional 21-hydroxylase gene (CYP21B), and a very closely related pseudogene (CYP21A) (Fig. 4). The two genes occur on tandem The repeated segments also contain other duplicated genes-namely, the complement $\mathrm{C} 4 \mathrm{~A}$ and genes. About $25 \%$ of pathological mutations at 1-hydroxylase locus are large deletions resultchange(Sinnott et al. 1990). The remaining $75 \%$ of mutations are point mutations where small-scale gene conversions of the CYP21B gene are thought to occur. A small segment of the CYP21A gene containing deleterious mutations is inserted into the CYP21B gene replacing a short segment of the original sequence. Analysis of one such mutation that arose de novo showed that the conversion tract was $390 \mathrm{bp}$ in length (Collier et al. 1993). Glucocorticoid-suppressible hyperaldosteronism (GSH) is an autosomal dominant form of hypertension caused by oversecretion of aldosterone. Gene fusion between the cytochrome P450 genes CYP11B1 and CYP11B2 has been shown to cause GSH (Lifton et al. 1992). CYP11B1 and CYP11B2 are two highly homologous genes closely linked on chromosome 8q22 that encode steroid biosynthetic enzymes catalyzing cortisol production and aldosterone production under the control of corticotrophin (ACTH) and angiotensin, respectively. Production of a hybrid gene due to unequal 


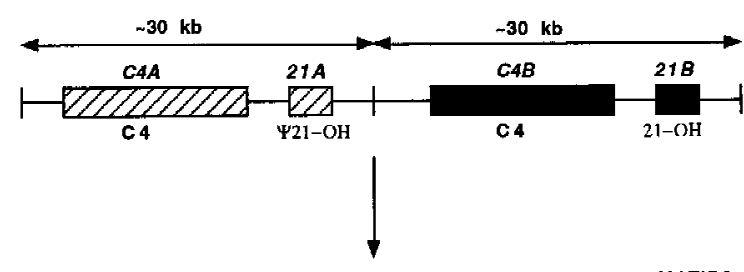

UNEQUAL PAIRING OF SISTER OR NON-SISTER CHROMATIDS

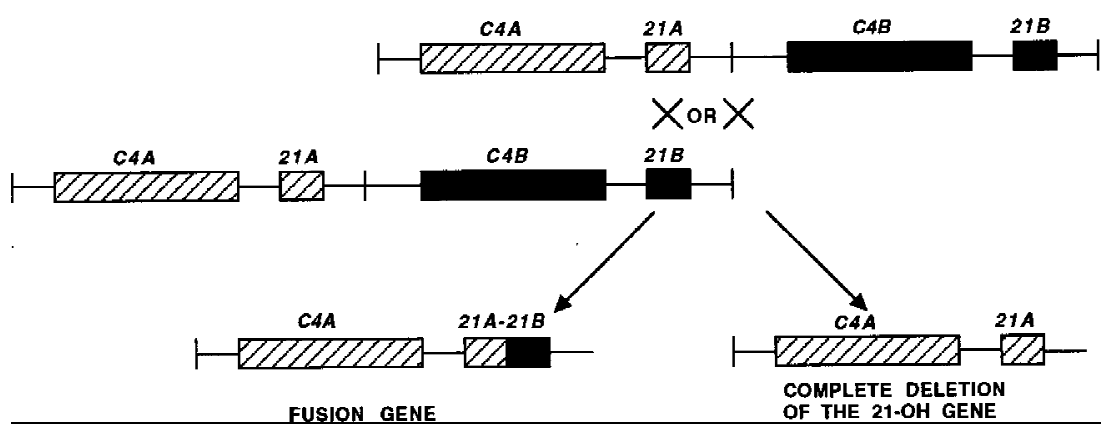

Figure 4 Steroid 21-hydroxylase gene mutations as a result of exchange of sequence between the functional 21-hydroxylase gene (21B) and its closely related pseudogene (21A). The duplicated complement genes (C4A and $\mathrm{C} 4 \mathrm{~B}$ ) and steroid 21-hydroxylase genes (21A and 21B) located on tandem $30-\mathrm{kb}$ repeats are shown. Unequal crossover or unequal sister chromatid exchange results in either formation of a fusion gene or complete deletion of the functional 21-hydroxylase gene.

meiotic crossing-over between CYP11B1 and CYP11B2 results in a new gene that contains the promoter of CYP11B1 and the coding region of CYP11B2. This fusion gene produces an enzyme that catalyzes the formation of aldosterone but is sensitive to ACTH. As a result, normal levels of ACTH, which normally maintain low levels of cortisol, lead to excessive production of aldosterone with consequent hypertension and hypokalemia.

The genes involved in visual dichromacy or red/ green color blindness are those encoding the red and green visual pigments. These are highly homologous ( $98 \%$ sequence identity in exons, introns, and $3^{\prime}$ flanking regions) and are linked in tandem on chromosome $\mathrm{Xq28}$. The red/green gene arrays are composed of a single red pigment gene and one or more green pigment genes located downstream $\left(3^{\prime}\right)$ of the red pigment gene. Gene expression studies indicate that when several green pigment genes are present, only the most proximal is expressed in the retina. Deficiencies in red/green color vision arise from unequal recombination of these normal X-linked genes (Nathans et al. 1986). Such events lead to deletions of the green pigment genes or the formation of full-length hybrid genes consisting of portions of both red and green pigment genes. (Fig. 5). With a few exceptions, del etion of the green pigment genes leaves a single red pigment gene and is associated with deuteranopia $(\mathrm{G}-\mathrm{R}+)$. Affected individuals are dichromatic, as they completely lack green cones. Individuals with 5'-green-red-3' fusion genes have deuteranomaly $\left(G^{\prime} R+\right)$, a milder type of color vision defect, with a slightly red-shifted absorption maximum for the green pigment. Individuals with 5'-red-green-3' fusion genes are associated with protan abnormalities ( $\mathrm{R}$ - or $\left.\mathrm{R}^{\prime}\right)$. Those who have a hybrid gene only are always protanopic ( $\mathrm{R}-$ ) and are therefore, dichromats. Those who have normal green genes in addition are either protanopic $(R-)$ or protanomalous ( $\left.R^{\prime}\right)$ and have a milder defect with slightly green-shifted absorption maximum of the red pigment.

Hybrid SMN (survival motor neuron) genes have been identified in patients with autosomal recessive spinal muscular atrophy (SMA) (Hahnen et al. 1996). The SMN gene is a strong candidate for SMA and is present as two highly homologous copies, telomeric SMN and centromeric SMN (TELSM N and CENSMN, respectively) within the SMA region. A large percentage of SM A patients (90\%-98\%) carry homozygous del etions in TELSM N, affecting either exon 7 or both exons 7 and 8 . Hybrid SMN genes were identified in 42 patients with SMA, who showed homozygous deletions of exon 7 but not of exon 8 of the TELSM N copy (Fig. 6). Besides the SMN gene, which is present in at least two copies per chromosome, all other genes and markers present in the SMA region are also present in several copies, and these regions are prone to unequal crossing-over resulting in deletions, duplications, and gene conversion events. A putative recombination hot spot represented by recombination-stimulating sequence el ements (TGGGG and TGAGGT) was identified in exon 8 of the SMN gene. These sequences are homologous to polymerase arrest sites (Weaver and DePamphilis 1982) and the deletion hot spot consensus sequences in the immunoglobulin switch region (Gritzmacher 1989) and the $\alpha$-globin gene cluster (Nicholls et al. 1987).

Sex-Specific M eiotic Recombination Hot Spots

Meiotic recombination in the genome does not oc- 
PURANDARE AND PATEL

A

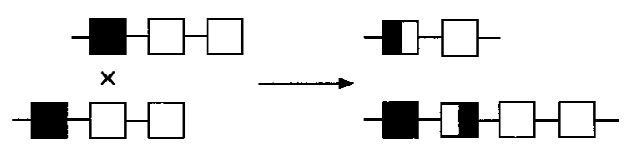

B

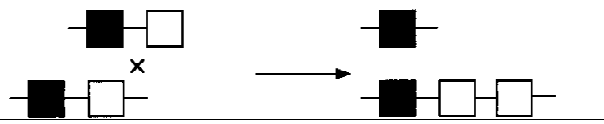

Figure 5 Unequal recombination in the color vision gene cluster. Unequal recombination resulting in creation of fusion genes (A) or loss of genes (B) is shown. ( $\boldsymbol{\square})$ Red cone pigment gene; $(\square)$ green cone pigment gene.

cur randomly but tends to be concentrated in hot spots, regions with relatively high recombination rates separated by stretches of diminished recombination. There is a striking sexual dimorphism in cytogenetic chromosome length, with human female pachytene chromosomes being 50\% longer than those in males (Wallace and Hulten 1985). It seems likely that the higher rate of recombination seen in human females versus males is a reflection of the more condensed state of male chromosomes. Chromatin conformation may influence meiotic recombination in humans. This is suggested by the observation that during spermatogenesis, the $X$ and $Y$ chromosomes are transcriptionally inactive and experience restriction of recombination, whereas the $X$ chromosomes, which are transcriptionally active during oogenesis, participate in unrestricted recombination (Handel and Hunt 1992). Recombination is probably prevented during meiosis in males by specific heterochromatization of the sex chromosomes (McKee and Handel 1993). There is virtual absence of crossing-over in constitutive heterochromatin, which is highly condensed and devoid of transcribed genes; this may be further evidence for an influence of chromatin structure on recombination.

In an effort to determine the pattern of chromatin condensation and recombination at meiosis in an imprinted region, Robinson and Lalande (1995) carried out fine-scale genetic mapping in the 4-Mb Angelman Syndrome/Prader-Willi Syndrome (AS/PWS) region. Their results indicated that the male/female recombination ratio varies significantly over short regions. A male recombination hot spot was localized to a region that is adjacent to, but outside, the putative AS/PWS-imprinted regions. In females, a region of relatively high recombination was observed that spans a domain of paternal allele specific transcription, implicated in the PraderWilli syndrome.
The preponderance of CMT1A duplication and factor VIII gene inversion in the male germ line has been discussed in the previous sections.

Proteins Involved in Homologous Recombination and their Role in Cancer

Human cancer is commonly associated with rearrangements of DNA that result in deletions of tumor suppressors and altered expression or amplification of proto-oncogenes. Multiple mutations are present in most human tumors, and these genetic modifications appear to be necessary to produce and select premalignant, malignant, and metastatic cells. Destabilization of genes in cancer could be explained by pre-existing hot spots or by creation of de novo hot spots by the rearrangements themselves. In this section proteins involved in homologous recombination, and "recombination hotspot-binding" proteins and their role in carcinogenesis are discussed.

Homologous recombination is a fundamental biological process, the biochemical understanding of which is most advanced in $\mathrm{E}$. coli. The proteins involved in promoting genetic exchange include

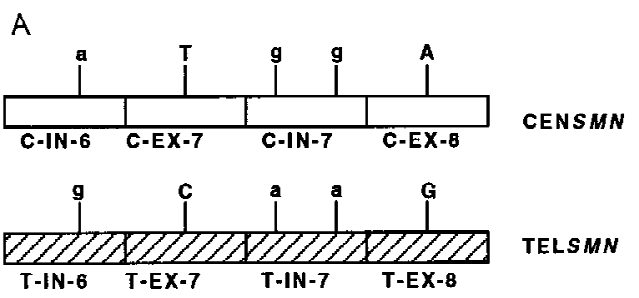

B

HYBRID GENES
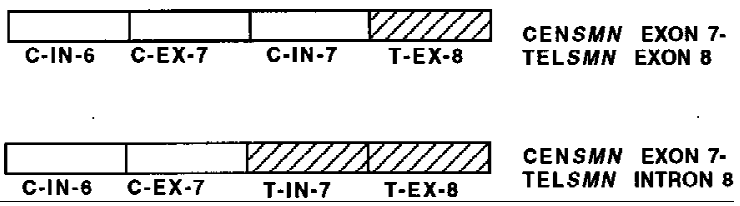

Figure 6 Generation of hybrid SM N genes. (A) The two highly homologous copies of the SM N gene, centromeric SMN (CENSMN) and telomeric SMN (TELSM N) are depicted. The two copies are distinguished by base changes in introns (IN) 6 and 7 and exons (EX) 7 and 8 as shown. The bases within introns and exons are depicted as lower- and uppercase, respectively. (B) Of the 42 patients examined (Hahnen et al. 1996), 40 showed hybrid genes containing CENSM N introns 6 and 7 and exon 7, and TELSM N exon 8; 2 of the 42 patients had a hybrid gene containing CENSM N intron 6 and exon 7, and TELSM N intron 7 and exon 8. 
RecA, RecBCD (exonuclease V), RecE (exonuclease VIII), RecF, RecG, RecJ, RecN, RecOR, RecQ, RecT, RuvAB, RuvC, SbcCD, SSB proteins, DNA polymerase I, DNA gyrase, DNA topoisomerase I, DNA ligase, and DNA helicases. Collectively, they define biochemical events essential for efficient recombination (Kowalczykowski et al. 1994). In addition to these proteins, a cis-acting recombination hot spot sequence chi (5'-GCTGGTGG-3'), is also known to play an important role (Smith 1989). The central events in homologous recombination are the pairing of homologous molecules and the initiation of strand exchange. The E. coli RecA protein is the prototype of proteins that can catalyze these reactions by promoting interaction between homologous DNA molecules (Kowalczykowski and Eggleston 1994). Evidence is accumulating that all organisms have a protein that shares significant functional homology to this bacterial protein, suggesting that the fundamental mechanisms of recombination are conserved in all species (Heyer 1994). Homologs of RecA are known in yeast (Saccharomyces cerevisiae; ScRad51) (Aboussekhra et al. 1992; Basile et al. 1992; Shinohara et al. 1992); mouse (M mRad51) (Morita et al. 1993); and human (HsRad51) (Shinohara et al. 1993; Yoshimura et al. 1993).

Genes involved in recombination in the yeast S. cerevisiae include those of the RAD52 epistasis group (RAD50-RAD57), involved in meiotic and mitotic recombination (Shinohara et al. 1993; Bishop 1994) and double strand break (DSB) repair (Game 1993). Accurate repair of these genotoxic lesions is essential for the prevention of chromosomal fragmentation, translocations, and deletions, which can lead to carcinogenesis through activation of oncogenes and/or inactivation of tumor suppressor genes. Key genes in the RAD52 DNA repair pathway include RAD 54 and RAD 51. The primary sequence of many RAD52 group genes is conserved from yeast to human. Analysis of the phenotype of mouse MmRad54 - / - cells by Essers et al. (1997) demonstrated that homologous recombination in these cells was reduced compared to wild-type cells, implying that homologous recombination contributes to the repair of DSBs in mammalian cells.

ScRad51 mutants also show defects in genetic recombination and repair of damaged DNA (Game 1993). A role of ScRad51 in meiosis is shown by its presence in meiotic nuclei al ong with SCDMC1, another homolog of RecA specific to mei osis (Bishop et al. 1992). Evidence for the role of HsRad51 protein in meiosis comes from the findings that antibody to HsRad51 stained murine synaptonemal complexes early in meiosis, and stained numerous foci in nu- clei of human cells exposed to DNA-damaging agents (Haaf et al. 1995; Plug et al. 1996). The role of the MmRad51 gene in mitosis and meiosis was shown by the finding of high levels of transcription of homologs of the Rad51 gene in lymphoid and reproductive organs (Shinohara et al. 1993). A homozygous MmRad51 mutation (MmRad51 - /-) was lethal early in murine embryogenesis (Tsuzuki et al. 1996). Lim and Hasty (1996) showed that the embryonic lethal phenotype of MmRad51 - / - is suppressed by a mutation in the p53 oncogene. Sturzbecher et al. (1996) reported that p53 interacts with HsRad51 and RecA. These observations suggest that functional wild-type p53 may select directly the appropriate path way for DNA repair and control the extent and timing of the production of genetic variation via homologous recombination. Therefore, rearrangements may occur as a direct consequence of a defect in p53-mediated control of homologous recombination processes attributable to mutations in the p53 gene.

Individuals with mutations in either the BRCA 1 or BRCA2 tumor suppressor genes have a dominant predisposition to breast and ovarian cancer (Smith et al. 1992; Easton et al. 1993; Wooster et al. 1994; Gayther et al. 1997). Colocalization and coimmunoprecipitation experiments have shown that human BRCA1 protein associates with HsRad51 in mitotic and meiotic cells (Scully et al. 1997). Thus, there appears to be a role for BRCA1 in nucl ear processes that leads to normal chromosomal recombination and control of genome integrity. Embryonic lethality and radiation hypersensitivity mediated by Rad51 was shown in mice lacking Brca2 (Sharan et al. 1997). Using a yeast two-hybrid assay, Sharan et al. 1997 also identified an interaction between Brca2 and MmRad51. The homozygous mutant phenotypes of Brca1, Brca2, and Mmrad51 are similar, indicating that these genes function in similar pathways (Hakem et al. 1996; Lim and Hasty 1996; Sharan et at 1997). The association of Rad51 with Brcal and Brca2 and the resultant sensitivity of MmRad51 - / - and Brca2 - / - cells to irradiation may explain the high penetrance of early onset cancer phenotypes exhibited by patients with either BRCA 1 or BRCA 2 mutations. In mammary epithelial cells that have lost BRCA1 or BRCA2 activity, the HsRad51-mediated DNA repair mechanisms may be compromised, thus destabilizing the genome. Thus, Rad51 probably suppresses tumor formation through its interaction with both Brcal and Brca2, all three of which may be involved in detecting and repairing DSBs, thereby controlling cell cycle progression (Sharan et al. 1997). 
A recombination hotspot-binding protein, translin, which is associated with chromosome translocations and binds to consensus sequences at breakpoint junctions of chromosomal translocations in many lymphoid malignancies, was reported by Aoki et al. (1995). ReHF-1, a recombination hot spot-associated factor specifically recognizes novel target sequences at the sites of interchromosomal rearrangements in T-cell acute lymphoblastic leukemia (T-ALL) (Kasai et al. 1994). Nuclear proteins have been identified that bind to target sequences within the recombination hot spot regions of the $\mathrm{BCl}-2$ oncogene that is involved in rearrangements associated with follicular lymphomas (Aoki et al. 1994). These proteins appear to be similar to ReHF1. Nuclear proteins were also shown to bind to the recombination hot spot region of the retinoic acid receptor $\alpha$ gene on chromosome 17 (Tashiro et al. 1994, 1995), which along with the PML gene on chromosome 15 is involved in the 15;17 translocations found in acute promyelocytic leukemia. The interaction of these proteins with conserved target sequences at chromosomal breakpoint junctions suggests that they may be involved in enzymatic mechanisms reminiscent of the general features of DNA recombination or replication events in $\mathrm{E}$. coli or S. cerevisiae.

Recombination is of eminent importance in germ cells to generate genetic diversity during meiosis and to safeguard DNA from genotoxic damage in somatic cells. Identification of human homologs of genes encoding components of the recombination and replication pathways of lower organisms will yield insight into mechanisms of disruption of these pathways that lead to human disease. Further characterization of the human genome has allowed identification of previously unknown sequence elements that may be involved in the recombination process. Understanding the complex mutational mechanisms in disease genes will allow us to discover new hot spots and mechanisms of recombination resulting in human disease.

\section{REFEREN CES}

Aboussekhra, A., R. Chanet, A. Adjiri, and F. Fabre. 1992. Semidominant suppressors of Srs2 helicase mutations of Saccharomyces cerevisiae map in the RAD51 gene, whose sequence predicts a protein with similarities to prokaryotic RecA proteins. Mol. Cell. Biol. 12: 3224-3234.

Aoki, K., K. Nakahara, C. Ikegawa, M. Seto, T. Takahashi, J. Minowada, J.L. Strominger, R.T. Maziarz, and M. Kasai. 1994. Nuclear proteins binding to a novel target sequence within the recombination hotspot regions of $\mathrm{BCl}-2$ and the immunoglobulin DH family. Oncogene 9: 1109-1115.
Aoki, K., K. Suzuki, T. Sugano, T. Tasaka, K. Nakahara, O. Kuge, A. Omori, and M. Kasai. 1995. A novel gene Translin encodes a recombination hotspot binding protein associated with chromosome translocations. Nature Genet.

10: $167-174$

Badr, F.M., P.A. Lorkin, and H. Lehmann 1973. Hemoglobin P Nilotic containing a $\beta-\delta$ chain. Nature 242: 107-110.

Baglioni, C. 1962. The fusion of two peptide chains in hemoglobin Lepore and its interpretation as a genetic deletion. Proc. Natl. Acad. Sci. 48: 1880-1886.

Ballabio, A., B. Bardoni, R. Carrozzo, G. Andria, D. Bick, L. Campbell, B. Hamell, M.A. Ferguson-Smith, G. Gimelli, M. Fraccaro, P. Maraschio, O. Zuffardi, S. Guioli, and G. Camerino. 1989a. Contiguous gene syndrome due to deletions in the distal short arm of the human $X$ chromosome. Proc. Natl. Acad. Sci. 86: 10001-10005.

Ballabio, A., R. Carozzo, G. Parenti, A. Gil, M. Zollo, M.G. Perisco, E. Gillard, N. Affara, J. Yates, M.A. Ferguson-Smith, R.R. Frants, A.W. Eriksso, and G. Andria. 1989b. Molecular heterogeneity of steroid sulfatase deficiency: A multicenter study on 57 unrelated patients at DNA and protein levels. Genomics 4: 36-40.

Barnabus, J. and C.J. Muller. 1962. Hemoglobin Lepore Hollandia. Nature 194: 931-932.

Basile, G., M. Aker, and R.K. Mortimer. 1992. Nucleotide sequence and transcriptional regulation of the yeast recombinational repair gene RAD51. Mol. Cell. Biol. 12: 3235-3246.

$\mathrm{Bi}, \mathrm{X}$. and L.F. Liu. 1996. Replicational model for DNA recombination between direct repeats. J. Mol. Biol. 256: 849-858.

Bishop, D.K. 1994. RecA homologs Dmcl and Rad51 interact to form multiple nuclear complexes prior to meiotic chromosome synapsis. Cell 79: 1081-1092.

Bishop, D.K., D. Park, L. Xu, and N. Kleckner. 1992. DMC1: A meiosis-specific yeast homologue of $E$. coli RecA required for recombination, synaptonemal complex formation, and cell cycle progression. Cell 9: 439-456.

Blair, I.P., J. Nash, M.J. Gordon, and G.A. Nicholson. 1996. Prevalence and origin of de novo duplications in Charcot-Marie-Tooth disease type 1a-first report of a de novo duplication with a maternal origin. Am. J. Hum. Genet. 58: 472-476.

Bondeson, M.L., N. Dahl, H. Malmgren, W.J. Kleijer, T. Tonnesen, B.M. Carlberg, and U. Pettersson. 1995. Inversion of the IDS gene resulting from recombination with IDS-related sequences is a common cause of the Hunter syndrome. Hum. Mol. Genet. 4: 615-621.

Bonifas, J.M., B.J. Morley, R.E. Oakley, Y.W. Kan, and E.H. Epstein, Jr. 1987. Cloning of a cDNA for steroid sulfatase: Frequent occurrence of gene deletions in patients with 
recessive $X$ chromosome linked icthyosis. Proc. Natl. Acad. Sci. 84: 9248-9251.

Chance, P.F., N. Abbas, M.W. Lensch, L. Pentao, B.B. Roa, P.I. Patel, and J.R. Lupski. 1994. Two autosomal dominant neuropathies result from reciprocal DNA

duplication/deletion of a region on chromosome 17. Hum. Mol. Genet. 3: 223-228.

Chen, E.Y., M. Zollo, R. Mazzarella, A. Ciccodicola, C.-N. Chen, L. Zuo, C. Heiner, F. Burrough, M. Repetto, D. Schlessinger, and M. D'Urso. 1996. Long-range sequence analysis in Xq28: Thirteen known and six candidate genes in $219.4 \mathrm{~kb}$ of high GC DNA between the RCP/GCP and G6PD loci. Hum. Mol. Genet. 5: 659-668.

Clark, L.N., U. Koehler, D.C. Ward, J. Wienberg, and J.E. Hewitt. 1996. Analysis of the organisation and localisation of the FSHD-associated tandem array in primatesimplications for the origin and evolution of the $3.3 \mathrm{~kb}$ repeat family. Chromosoma 105: 180-189.

Collier, P.S., M. Tassabehji, P.J. Sinnott, and T. Strachan. 1993. A de novo pathological point mutation at the 21-hydroxylase locus: Implications for gene conversion in the human genome. Nature Genet. 3: 260-265.

Conary, J.T., G. Lorkowski, B. Schmidt, R. Pohlmann, G. Nagel, H.E. Meyer, C. Krentler, J. Tully, A. Hasilik, and K. von Figura. 1987. Genetic heterogeneity of steroid sulfatase deficiency revealed with cDNA for human steroid sulfatase. Biochem. Biophys. Res. Commun. 144: 1010-1017.

Dozy, A.M., Y.W. Kan, S.H. Embury, W.C. Mentzer, W.C. Wang, B. Lubin, J.R. Davis, and H.M. Koenig. 1979. $\alpha$-Globin gene organisation in blacks precludes the severe form of $\alpha$-thalassemia. Nature 280: 605-607.

Easton, D.F., D.T. Bishop, D. Ford, G.P. Crockford, and the Breast Cancer Linkage Consortium. 1993. Genetic linkage analysis in familial breast and ovarian cancer: Results from 214 families. Am. J. Hum. Genet. 52: 678-701.

Embury, S.H., J.A. Miller, A.M. Dozy, Y.W. Kan, V. Chan, and D. Todd. 1980. Two different molecular organizations account for the single $\alpha$-globin gene of the $\alpha$-thalassemia- 2 genotype. J. Clin. Invest. 66: 1319-1324.

Essers, J., R.W. Hendriks, S.M.A. Swagemakers, C. Troelstra, J. de Wit, D. Bootsma, J.H.J. Hoeijmakers, and R. Kanaar. 1997. Disruption of mouse RAD54 reduces ionizing radiation reistance and homologous recombination. Cell 89: 195-204.

Game, J.C. 1993. DNA double-strand breaks and the RAD50-RAD57 genes in Saccharomyces. Semin. Cancer Biol. 4: $73-83$.

Gayther, S.A., J. Mangion, P. Russell, S. Seal, R. Barfoot, B.A. Ponder, M.R. Stratton, and D. Easton. 1997. Variation of risks of breast and ovarian cancer associated with different germline mutations of the BRCA2 gene. Nature Genet. 15: 103-105.

\section{RECOMBINATION HOT SPOTS AND HUMAN DISEASE}

Gerald, P.S. and L.K. Diamond. 1958. A new hereditary hemoglobinopathy (the Lepore trait) and its interaction with the thalassemia trait. Blood 13: 835-844.

Goosens, M., A.M. Dozy, S.H. Embury, Z. Zachariades, M.G. Hadjiminas, G. Stamatoyannopoulos, and Y.W. Kan. 1980. Triplicated $\alpha$-globin loci in humans. Proc. Natl. Acad. Sci. 77: $518-521$.

Gritzmacher, C.A. 1989. Molecular aspects of heavy-chain class switching. Crit. Immunol. 9: 173-200.

Haaf, T., E.I. Golub, G. Reddy, C.M. Radding, and D.C. Ward. 1995. Nuclear foci of mammalian Rad51 recombination protein in somatic cells after DNA damage and its localization in synaptonemal complexes. Proc. Natl. Acad. Sci. 92: 2298-2302.

Hahnen, E., J. Schonling, S. Rudnikschoneborn, K. Zerres, and B. Wirth. 1996. Hybrid survival motor neuron genes in patients with autosomal recessive spinal muscular atrophy-new insights into molecular mechanisms responsible for the disease. Am. J. Hum. Genet.

59: 1057-1065.

Hakem, R., J.L. de la Pompa, C. Sirard, R. Mo, M. Woo, A. Hakem, A. Wakeham, J. Potter, A. Reitmair, F. Billia, E. Firpo, C.C. Hui, J. Roberts, J. Rossant, and T.W. Mak. 1996. The tumor suppressor gene Brcal is required for embryonic cellular proliferation in the mouse. Cell 85: 1009-1023.

Handel, M.A. and P.A. Hunt. 1992. Sex chromosome pairing and activity during mammalian meiosis. BioEssays 12: 817-822.

Hardman, N. 1986. Structure and function of repetitve DNA in eukaryotes. Biochem. J. 234: 1-11.

Hertz, J.M., A.D. Borglum, C.A. Brandt, T. Flint, and C. Bisgaard. 1994. Charcot-Marie-Tooth disease type 1A: The parental origin of a de novo 17p11.2-p12 duplication. Clin. Genet. 46: 291-294.

Hewitt, J.E., R. Lyle, L.N. Clark, E.M. Valleley, T.J. Wright, C. Wijmenga, J.C. van Deutekom, F. Francis, P.T. Sharpe, M. Hofker, R.R. Frants, and R. Williamson. 1994. Analysis of the tandem repeat locus D4Z4 associated with facioscapulohumeral muscular dystrophy. Hum. Mol. Genet. 3: 1287-1295.

Heyer, W.D. 1994. The search for the right partner: Homologous pairing and DNA strand exchange proteins in eukaryotes. Experientia 50: 223-233.

Higgs, D.R., J.M. Old, J.B. Clegg, L. Pressley, D.M. Hunt, D.J. Weatherall, and G.R. Serjeant. 1979. Negro $\alpha$-thalassemia is caused by deletion of a single $\alpha$-globin gene. Lancet 2: $272-276$.

Higgs, D.R., M.A. Vickers, A.O.M. Wilkie, I-M. Pretorius, A.P. Jarman, and D.J. Weatherall. 1989. A review of the molecular genetics of the $\alpha$-globin gene cluster. Blood 73: 1081-1104. 
Honig, G.R., R.G. Mason, L.M. Tremaine, and L.N. Vida. 1978. Unbalanced globin chain synthesis by $\mathrm{Hb}$ Lincoln Park (anti-Lepore) reticulocytes. Am. J. Hematolol. 5: $335-340$.

Huisman, T.H.J., R.N. Wrightstone, J.B. Wilson, W.A. Schroeder, and A.G. Kendal. 1972. Hemoglobin Kenya, the product of a fusion of $\gamma$ and $\beta$ polypeptide chains. Arch. Biochem. Biophys. 153: 850-853.

Jelinek, W.R., and C.W. Schmid. 1982. Repititive sequences in eukaryotic DNA and their expression. Annu. Rev. Biochem. 51: 831-844.

Kasai, M., K. Aoki, Y. Matsuo, J. Minowada, R.T. Maziarz, and J.L. Strominger. 1994. Recombination hotspot associated factors specifically recognize novel target sequences at the site of interchromosomal rearrangements in T-ALL patients with $t(8 ; 14)(q 24 ; q 11)$ and $t(1 ; 14)$ (p32;q11). Int. Immunol. 6: 1017-1025.

Kiyosawa, H. and P.F. Chance. 1996. Primate origin of the CMTIA-REP repeat and analysis of a putative transposon-associated recombination hotspot. Hum. Mol. Genet. 5: 745-754.

Konrad, M., S. Saunie, L. Heidet, F. Silbermann, F. Benessy, J. Calado, D. Lepaslier, M. Broyer, M.C. Gubler, and C. Antignac. 1996. Large homozygous deletions of the $2 q 13$ region are a major cause of juvenile nephronophthisis. Hum. Mol. Genet. 5: 367-371.

Kowalczykowski, S.C. and A.K. Eggleston. 1994. Homologous pairing and DNA strand-exchange proteins. Annu. Rev. Biochem. 63: 991-1043.

Kowalczykowski, S.C., D.A. Dixon, A.K. Eggleston, S.D. Lauder, and W.M. Rehrauer. 1994. Biochemistry of homologous recombination in Escherichia coli. Microbiol. Rev. 58: 401-465.

Krawczak, M. and D.N. Cooper. 1991. Gene deletions causing human genetic disease: Mechanisms of mutagenesis and the role of the local DNA sequence environment. Hum. Genet. 86: 425-441.

Lakich, D., H.H. Kazazian, Jr., S.E. Antonarakis, and J. Gitschier. 1993. Inversions disrupting the factor VIII gene are a common cause of severe haemophilia A. Nature Genet. 5: $236-241$.

Lauer, J., C.-K.J. Chen, and T. Maniatis. 1980. The chromosomal arrangement of human $\alpha$-like globin genes: Sequence homology and $\alpha$-globin gene deletions. Cell 20: $119-130$.

Lee, J.H., K. Goto, C. Matsuda, and K. Arahata. 1995. Characterization of a tandemly repeated 3.3-kb Kpnl unit in the facioscapulohumeral muscular dystrophy (FSHD) gene region on chromosome 4q35. Muscle \& Nerve 2: 6-13.

Lehmann, H. and D. Charlesworth. 1970. Observations on hemoglobin P (Congo type). Biochem J. 119: 43.
Lehrman, M.A., W.J. Schneider, T.C. Sudhof, M.S. Brown, J.L. Goldstein, and D.W. Russell. 1985. Mutation in LDL receptor: Alu-Alu recombination deletes exons encoding transmembrane and cytoplasmic domains. Science 227: $140-146$.

Lehrman, M.A., D.W. Russell, J.L. Goldstein, and M.S. Brown. 1987. Alu-Alu recombination deletes splice acceptor sites and produces secreted low density lipoprotein receptor in a subject with familial hypercholesterolemia. J. Biol. Chem. 262: 3354-3356.

Leib-Mosch, C. and W. Seifarth. 1995. Evolution and biological significance of human retroelements. Virus Genes 11: $133-145$.

Li, X-M., P.H. Yen, and L.J. Shapiro. 1992. Characterization of a low copy repetitive element $\mathrm{S} 232$ involved in the generation of frequent deletions of the distal short arm of the human X chromosome. Nucleic Acids Res.

\section{0: $1117-1122$.}

Lifton, R.P., R.G. Dluhy, M. Powers, M. Rich, S. Cook, S.

Ulick, and J.-M. Lalouel. 1992. A chimaeric

11-hydroxylase/aldosterone synthase gene causes glucocorticoid-remediable aldosteronism and human hypertension. Nature 355: 262-265.

Lim, D.-S. and P. Hasty. 1996. A mutation in Mouse rad51 results in an early embryonic lethal that is suppressed by a mutation in p53. Mol. Cell. Biol. 16: 7133-7143.

Lyle, R., T.J. Wright, L.N. Clark, and J.E. Hewitt. 1995. The FSHD-associated repeat, D4Z4, is a member of a dispersed family of homeobox-containing repeats, subsets of which are clustered on the short arms of the acrocentric chromosomes. Genomics 28: 389-397.

McKee, B.D. and M.A. Handel. 1993. Sex chromosomes, recombination and chromatin conformation. Chromosoma 102: $71-80$.

Morita, T., Y. Yoshimura, A. Yamamoto, K. Murata, M. Mori, H. Yamamoto, and A. Matsushiro. 1993. A mouse homologue of the Escherichia coli RecA and Saccharomyces cerevisiae RAD51 genes. Proc. Natl. Acad. Sci. 90: 6577-6580.

Nathans, J., D. Thomas, and D.S. Hogness. 1986. Molecular genetics of human color vision: The genes encoding blue, green and red pigments. Science 232: 193-202.

Nicholls, R.D., N. Fischel-Ghodsian, and D.R. Higgs. 1987. Recombination at the human alpha-globin gene cluster: Sequence features and topological constraints. Cell 49: 369-378.

Ohta, Y., K. Yamaoka, I. Sumida, S. Fujita, T. Fujimura, M. Hadana, and T. Yanase. 1970. Two structural and synthetical variants, $\mathrm{Hb}$ Miyada and homozygous $\delta$-thalassemia, discovered in Japanese. XIII International Congress of Haematology, Verlag, Munich, Germany.

Ostertag W. and E.W. Smith. 1969. Hemoglobin-Lepore- 
Baltimore, a third type of a $\delta-\beta$ crossover $(\delta 50, \beta 86)$. Eur. J. Biochem. 10: 371-376.

Palau, F., A. Lofgren, P. De Jonghe, S. Bort, E. Nelis, T. Sevilla, J.J. Martin, J. Vilchez, F. Prieto, and C. Van Broeckhoven. 1993. Origin of the de novo duplication in Charcot-Marie-Tooth disease type 1A: unequal nonsister chromatid exchange during spermatogenesis. Hum. Mol. Genet. 2: 2031-2035.

Patel, P.I., and J.R. Lupski. 1994. Charcot-Marie Tooth disease: A new paradigm for the mechanism of inherited disease. Trends Genet. 10: 128-133.

Pentao, L., C.A. Wise, A.C. Chinault, P.I. Patel, and J.R. Lupski. 1992. Charcot-Marie-Tooth type 1A duplication appears to arise from recombination at repeat sequences flanking the $1.5 \mathrm{Mb}$ monomer unit. Nature Genet. 2: 292-300.

Plug, A.W., J. Xu, G. Reddy, E.I. Golub, and T. Ashley. 1996. Presynaptic association of Rad51 protein with selected sites in meiotic chromatin. Proc. Natl. Acad. Sci. 93: 5920-5924.

Raeymaekers P., V. Timmerman, E. Nelis, P. De Jonghe, J.E. Hoogendijk, F. Bass, D.F Barker, J.J. Martin, M. De Visser, P.A. Bolhuis, and C. Van Broeckhoven. 1991. Duplication in chromosome 17p11.2 in Charcot-Marie-Tooth neuropathy type 1a (CMT1A). Neuromusc. Disord. 1: 93-97.

Rathmann, M., S. Bunge, C. Steglich, E. Schwinger, and A. Gal. 1995. Evidence for an iduronate-sulfatase pseudogene near the functional Hunter syndrome gene in Xq27.3-q28. Hum. Genet. 95: 34-38.

Reiter, L.T., T. Murakami, T. Koeuth, L. Pentao, D. Muzny, R. Gibbs, and J. Lupski. 1996. A recombination hotspot responsible for two inherited peripheral neuropathies is located near a mariner transposon-like element. Nature Genet. 12: 288-297.

Robinson, W.P. and M. Lalande. 1995. Sex-specific meitoic recombination in the Prader-Willi/Angelman syndrome imprinted region. Hum. Mol. Genet. 4: 801-806.

Rossiter, J.P., M. Young, M.L. Kimberland, P. Hutter, R.P. Ketterling, J. Gitschier, J. Horst, M.A. Morris, D.J. Schaid, P. deM oerloose, S. Sommer, H.H. Kazazian, and S.E.

Antonarakis. 1994. Factor VIII gene inversions causing severe hemophilia A originate almost exclusively in male germ cells. Hum. Mol. Genet 3: 1035-1039.

Scully, R., J. Chen, A. Plug, Y. Xiao, D. Weaver, J. Feunteun, T. Ashley, and D.M. Livingston. 1997. Association of BRCA1 with Rad51 in mitotic and meiotic cells. Cell 88: 265-275.

Sharan, S.K., M. Morimatsu, U. Albrecht, D.-S. Lim, E. Regel, C. Dinh, A. Sands, G. Eichele, P. Hasty, and A. Bradley. 1997. Embryonic lethality and radiation hypersensitivity mediated by Rad51 in mice lacking Brca2. Nature 386: 804-810.

Shinohara, A., H. Ogawa, and T. Ogawa. 1992. Rad51 protein involved in repair and recombination in S. cerevisiae is a RecA-like protein. Cell 69: $457-470$.

Shinohara, A., H. Ogawa, Y. Matsuda, N. Ushio, K. Ikeo, and T. Ogawa. 1993. Cloning of human, mouse and fission yeast recombination genes homologous to RAD51 and RecA. Nature Genet. 4: 239-243.

Singer, M.F. 1982. SINEs and LINEs: Highly repeated short and long interspersed sequences in mammalian genomes. Cell 28: 433-434.

Sinnott, P.J., S. Collier, C. Costigan, P.A. Dyer, R. Harris, and T. Strachan. 1990. Genesis by meiotic unequal crossover of a de novo deletion that contributes to steroid 21-hydroxylase deficiency. Proc. Natl. Acad. Sci. 87: 2107-2111.

Small, K., J. Iber, and S.T. Warren. 1997. Emerin deletion reveals a common $\mathrm{X}$-chromosome inversion mediated by inverted repeats. Nature Genet. 16: 96-99.

Smith S.A., D.F. Easton, D.G. Evans, and B.A. Ponder. 1992. Allele losses in the region $17 q 12-21$ in familial breast and ovarian cancer involve the wild-type chromosome. Nature Genet. 2: 128-131.

Smith, G.R. 1989. Homologous recombination in E. coli: Multiple pathways for multiple reasons. Cell 58: 807-809.

Steen, V.M., A. Molven, N.K. Aarskog, and A.K. Gulbrandsen. 1995. Homologous unequal cross-over involving a $2.8 \mathrm{~kb}$ direct repeat as a mechanism for the generation of allelic variants of human cytochrome P450 CYP2D 6 gene. Hum. Mol. Genet. 4: 2251-2257.

Stoppa-Lyonnet, D., C. Duponchel, T. Meo, J. Laurent, P.E. Carter, M. Arala-Chaves, J.H. Cohen, G. Dewald, J. Goetz, G. Hauptmann, G. Lagrue, P. Lesavre, M. Lopez-Trascasa, G. Misiano, C. Moraine, A. Sobel, P.J. Spath, and M. Tosi. 1991. Recombinational biases in the rearranged C1-inhibitor genes of hereditary angioedema patients. Am. J. Hum. Genet. 49: 1055-1062.

Sturzbecher, H.W., B. Donzelmann, W. Henning, U. Knippschild, and S. Buchop. 1996. p53 is linked directly to homologous recombination processes via RAD51/RECA protein interaction. EMBO J. 15: 1992-2002.

Tashiro, S., N. Kotomura, K. Tanaka, K. Suzuki, T. Kyo, H. Dohy, O. Niwa, and N. Kamada. 1994. Identification of illegitimate recombination hot spot of the retinoic acid receptor alpha gene involved in 15;17 chromosomal translocation of acute promyelocytic leukemia. Oncogene 9: 1939-1945.

Tashiro S., Z.W. Wang, N. Kotomura, M. Eguchi, O. Niwa, K. Ueda, and N. Kamada. 1995. Nuclear proteins binding to the recombination hotspot region of the retinoic acid receptor alpha gene. Cancer Res. Ther. Control 4: 293.

Tsuzuki, T., Y. Fujii, K. Sakumi, Y. Tominaga, K. Nakao, M. Sekiguchi, A. Matsuhiro, Y. Yoshimura, and T. Morita. 1996. 


\section{PURANDARE AND PATEL}

Targeted disruption of the rad51 gene leads to lethality in embryonic mice. Proc. Natl. Acad. Sci. 93: 6236-6240.

van Deutekom, J.C., C. Wijmenga, E.A. van Tienhoven, A.M. Gruter, J.E. Hewitt, G.W. Padberg, G.J. van Ommen, M.H. Hofker, and R.R. Frants. 1993. FSHD-associated DNA rearrangements are due to deletions of integral copies of a $3.2 \mathrm{~kb}$ tandemly repeated unit. Hum. Mol. Genet. 2: 2037-2042.

Vnencak-Jones, C.L., J.A. Phillips III, E.Y. Chen, and P.H. Seeburg. 1988. Molecular basis of human growth hormone gene deletions. Proc. Natl. Acad. Sci. 85: 5615-5619.

Vnencak-Jones, C.L, and J.A. Phillips III. 1990. Hot spots for growth hormone gene deletions in homologous regions outside of Alu repeats. Science 250: 1745-1748.

Vogt, P. 1990. Potential genetic functions of tandem repeated DNA sequence blocks in the human genome are based on a highly conserved "chromatin folding code." Hum. Genet. 84: 301-306.

Wahls, W.P., L.J. Wallace, and P.D. Moore. 1990. Hypervariable minisatellite DNA is a hotspot for homologous recombination in human cells. Cell 60: 95-103.

Wallace, B.M.K. and M.A. Hulten. 1985. Meiotic chromosome pairing in the normal female. Annu. Hum. Genet. 49: 215-226.

Weaver, D.T. and M.L. DePamphilis. 1982. Specific sequences in native DNA that arrest synthesis by DNA polymerase $\alpha$. J. Biol. Chem. 257: 2075-2086.

Winokur, S.T., U. Bengtsson, J.C. Vargas, J.J. Wasmuth, and M.R. Altherr. 1996. The evolutionary distribution and structural organization of the homeobox-containing repeat D4Z4 indicates a functional role for the ancestral copy in the FSHD region. Hum. Mol. Genet. 5: 1567-1575.

Wise, C.A., C.A. Garcia, S.N. Davis, Z. Heju, L. Pentao, P.I. Patel, and J.R. Lupski. 1993. Molecular analyses of unrelated Charcot-Marie-Tooth (CMT) disease patients suggests a high frequency of the CMT1A duplication. Am. J. Hum. Genet. 53: 853-863.

Wooster, R., S.L. Neuhausen, J. Mangion, Y. Quirk, D. Ford, N. Collins, K. Nguyen, S. Seal, T. Tran, D. Averill, P. Fields, G. Marshall, S. Narod, G.M. Lenoir, H. Lynch, J. Feunteun, P. Devilee, C.J. Cornelisse, F.H. Menko, P.A. Daly, W. Orminston, R. McMannus, C. Pye, C.M. Lewis, L.A. Cannon-Albright, J. Peto, B.A.J. Ponder, M.H. Skolnick, D.F. Easton, D.E. Goldgar, and M.R. Stratton. 1994. Localization of a breast cancer susceptibility gene, BRCA2, to chromosome 13q12-13. Science 265: 2088-2090.

Yen, P.H., X-M. Li, S.-P. Tsai, C. Johnson, T. Mohandas, and L.J. Shapiro. 1990. Frequent deletions of the human $X$ chromosome distal short arm result from recombination between low copy repititive elements. Cell 61: 603-610.

Yoshimura, Y., T. Morita, A. Yamamoto, A. Matsushiro. 1993. Cloning and sequence of the human RecA-like gene cDNA. Nucleic Acids Res. 21: 1665. 


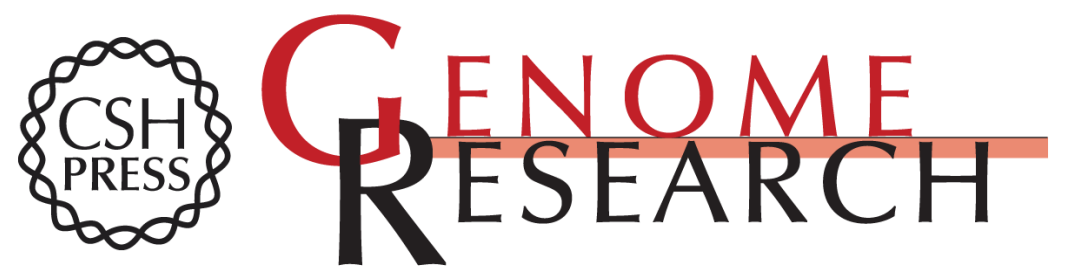

\section{Recombination Hot Spots and Human Disease}

Smita M. Purandare and Pragna I. Patel

Genome Res. 1997 7: 773-786

Access the most recent version at doi:10.1101/gr.7.8.773

References This article cites 95 articles, 23 of which can be accessed free at:

http://genome.cshlp.org/content/7/8/773.full.html\#ref-list-1

\section{License}

Email Alerting Receive free email alerts when new articles cite this article - sign up in the box at the Service top right corner of the article or click here.

\section{Affordable, Accurate Sequencing.}

To subscribe to Genome Research go to: https://genome.cshlp.org/subscriptions 